\title{
Adolescents' exposure to mass media campaign messages on HIV/AIDS in Ghana
}

\author{
Eugene Kofuor Maafo Darteh \\ Department of Population and Health, University of Cape Coast, Ghana \\ eugenedarteh@gmail.com
}

\begin{abstract}
Using rich data collected from adolescents in Ghana by the Guttmacher Institute in collaboration with partners including the University of Cape Coast, this paper attempts to examine how exposure to specific messages designed for a media campaign dubbed 'Stop AIDS-Love Life' affected adolescents' behaviour towards HIV/AIDS. Two logistic regression models are used to examine the effects of exposure to messages on HIVIAIDS on adolescents' behavior towards HIV/AIDS. The study observed a direct and significant relationship between exposure to some of the messages and HIV/AIDS behavioural outcomes. It was established that adolescents who were exposed to the message titled "Think before you play" were about I.3 times more likely to consider themselves at risk of HIV infection in both models. At $p<.05$, adolescents who reported exposure to HIV/AIDS messages "No means no - think" were more than I. $\square$ times more likely to express willingness to care for an HIV infected persons. The study highlights the need to put in place measures which will ensure that adolescents are reached with appropriate messages through mass media channels which are accessible to them. Efforts should be made to use mass media messages to reach adolescents on issues concerning HIV/AIDS stigma and discrimination. It is recommended that adolescents should be provided with supportive environments which will help them to sustain positive behaviour that they adopt in order to avoid a "slip" or "relapse". Also, program designers and implementers should avoid the 'once-size-all approach' and consider the heterogeneity that exists among adolescents in the design of campaign messages.
\end{abstract}

Key words: Adolescent; exposure; mass media; HIV/AIDS; Ghana

\section{Résumé}

En utilisant les données recueillies auprès des adolescents au Ghana par l'Institut Guttmacher, en collaboration avec des partenaires dont l'Université de Cape Coast, cet article tente d'examiner comment l'exposition à des messages spécifiques destinés à une campagne médiatique baptisée «Arrêtez les SIDA ! Aimez la vie! » a affecté le comportement des adolescents à l'égard du VIH / SIDA. Deux modèles de régression logistique sont utilisés pour examiner les effets de l'exposition à des messages à propos du VIH / SIDA sur le comportement des adolescents face au VIH / SIDA. L'étude a montré une relation directe et significative entre l'exposition à certains des messages et les résultats comportementaux du $\mathrm{VIH}$ / SIDA. Il a été établi que les adolescents qui ont été exposés au message intitulé "Réfléchissez avant de jouer" ont été environ I,3 fois plus susceptibles de se con- 
sidérer à risque d'infection du VIH dans les deux modèles. $A p<.05$, les adolescents qui ont déclaré être exposés aux messages du VIH / SIDA «Pas de moyens, Non! Réfléchissez !» ont été plus de I, $\square$ fois plus susceptibles d'exprimer leur volonté de prendre soin d'une personne infectée par le VIH. L'étude souligne la nécessité de mettre en place des mesures qui feront en sorte que les adolescents aient les messages appropriés par les médias de masse qui leur sont accessibles. Des efforts devraient être déployés pour utiliser les messages des médias de masse pour atteindre les adolescents sur les questions concernant la stigmatisation et la discrimination relatives au VIH / SIDA. II est recommandé que les adolescents accèdent aux environnements de soutien qui les aideront à maintenir un comportement positif qu'ils adoptent afin d'éviter une «erreur» ou «rechute». En outre, les concepteurs et exécutants de programmes devraient éviter le "une fois à taille tous les approche» et tenir compte de l'hétérogénéité qui existe chez les adolescents dans la conception des messages de campagne.

Mots-clés: Adolescents, l'exposition, les médias de masse, le VIH / SIDA; Ghana

\section{Introduction}

The mass media has been used for decades to communicate to the general populace on a broad range of issues. In the last decade or so, this has been intensified among adolescents in the era of HIV/AIDS for the purpose of promoting and enhancing behaviour change among different population groups. Since the outbreak of HIV/AIDS there have been several efforts at containing the epidemic. These have included among other things the use of the mass media and other medium of communication to reduce risky sexual behaviour which promotes the spread of HIV/ AIDS.

A number of studies (Hindin et al. 1984; Kim et al. 200I; Lewicky et al. 1998; Scheepers 200I; Piotrow et al. 1992; Underwood 200I; Westoff and Rodridguez, 1995; and Yoder et al. 1996) have looked at the effectiveness of using the mass media to provide information on contraceptives in a bid to change behaviour. These studies have established relationships between mass media exposure and contraceptive use in a number of countries including Ghana.

In recent times, other scholars have used cross sectional studies to establish the relationship between exposure to mass media channels and some reproductive health outcomes including HIV/ AIDS. Most of these studies have looked at channels used in the mass media such as radio, television, newspapers and so on. A recent study by Kwankye and Augustt (2007), for example, examined the possible impact of media channel on sex initiation and timing of marriage, knowledge of the ovulatory cycle, contraceptive knowledge and use, childbearing and pregnancy termination among young women in Ghana. Other studies like Benefo (2004) used logistic regression to examine how the exposure to HIV/AIDS information in the mass media influences knowledge of the disease and risk behaviour in Ghana. Studies have been conducted on mass media exposure in other parts of the world. For instance, Khan et al. (2004) examined the impact 
of various sources of AIDS information among ever married men and women in Bangladesh. This and many more studies have attempted to establish the effect of exposure to channels (television, radio and so on) of communication on behaviour towards HIV/AIDS. The common feature of the aforementioned studies is that they relied on data from Demographic and Health Surveillance data and also focused on mass media channels.

Studies have shown that in Ghana, HIV infection is high among young men and women in their 20's (NACP, 2009). Adolescents make up more than $30 \%$ of the population of the country and are among the most socially and sexually active groups. They also have limited knowledge of and lack access to resources and services on a range of issues including sexual and reproductive health (National Population Council, 2000). With this background, adolescents' would continue to play a crucial role in the fight against the HIV scourge. Also, because the mass media play a crucial role in the lives of the adolescent, many Information $\square$ ducation and Communication (I $\square$ C) or Behavioural Change Communication (BCC) programs on HIV/AIDS targeting adolescents have tended to use the mass media as the channel for communications.

Since the mass media is used for purposes other than effecting and promoting behaviour change, it is assumed that exposure to a particular medium of communication, be it radio, television, newspaper, alone may not necessarily lead to a positive behaviour towards HIV/AIDS among adolescents. This paper attempts to examine how expo- sure to specific messages designed for a media campaign dubbed "Stop AIDSLove Life' affected adolescents' behaviour towards HIV/AIDS in Ghana using data from a National Survey of Adolescents, 2004. The paper will also attempt to answer the question whether adolescents' exposure to messages in the media affect their behaviour towards HIV/AIDS.

\section{Literature review and theoretical framework}

The Johns Hopkins University's Centre for Communication (Ghana Office), Ghana Social Marketing Foundation (GSMF) and the National AIDS/STI Control Program (NACP) formed a consortium of partners and launched a National Campaign on HIV/AIDS targeted at young adults in February 2000. The campaign dubbed "Sop AIDS-Love Life" was meant to increase perception of risk, encourage social support for positive behavior such as condom use, and generate increased compassion for those living with AIDS (NACP, 200I).

With an estimated median HIV prevalence rate of about 2.2 per cent in 2008, the HIV prevalence rate in Ghana can be considered as low. However, it is reported to be firmly rooted in the whole Ghanaian society with higher prevalence recorded among certain sub-populations such as sex workers. This increased risk of transmission remains a reservoir for the sustenance of the epidemic. According the NACP, the national estimates for 2008 puts the cumulative HIV and AIDS population at 249,145 comprising 238,840 adults and 17,305 children with a cumulative death of 200,027 . HIV prevalence in Ghana varies by region, residence, age group 
and sex. For instance, prevalence at the regional level ranged from a low of I.I in the Northern region to a high of 4.2 in the astern region with urban areas having higher prevalence than rural areas. The highest prevalence in the urban areas was recorded in Agomanya in the Dastern region and the lowest in Tamale in the Northern region. The prevalence was 3.0 per cent among the age group 25-29 (the highest prevalence) and the least of 1.2 per cent was recorded among the 15-19 year olds. According to the National AIDS Control Programme (2009), prevalence among the youth aged 15-24 years was 1.9 per cent. In spite of the widespread information on HIV/AIDS, its incidence is still high and keeps increasing.

At the moment, there are radio stations scattered all over the country (at least one government-owned in each regional capital) with many privately operated ones. In addition, there are more than six television stations in the country and a lot in the print media. As a means of assessing the potential effectiveness of using media to broadcast messages on reproductive health issues such as family planning, the 2003 GDHS collected information on respondents' exposure to both broadcast and print media. Access to mass media, especially the broadcast media, is generally high in Ghana. For instance, $74 \%$ of women and $89 \%$ of men listen to the radio at least once a week, and $44 \%$ of women and $51 \%$ of men watch television at least once a week. On the other hand, exposure to the print media is relatively low. Twelve percent of women and $28 \%$ of men read a newspaper at least once a week. Men are twice as likely as women to be exposed to all three media sources $(23 \%$ and $10 \%$, respectively). Media exposure is higher among younger women (age I5-24) than older women (25 years and above). However, among men, exposure is lowest among those aged 15-19 and highest among those aged 20-29 (GSS, NMIMR, and ORC Macro, 2004). With a high access to the mass media especially the electronic; Ghana is a good setting for examining the relationship between the mass media message exposure and HIV/AIDS behavior.

This study, therefore, attempts to examine whether the efforts at fighting HIV/AIDS through the mass media has been effective thus far by establishing the relationships between exposure to specific messages designed for a media campaign dubbed "Stop AIDS, Love Life' and adolescents' behaviour towards HIV/AIDS. This paper intends to contribute to the effectiveness of the efforts geared towards the fight against HIV/AIDS using the mass media as a case study.

\section{Input/output persuasion model}

McGuire (1989) developed the hierarchy of communication effects and considered how various aspects of communication, such as message design, source, and channel, as well as audience characteristics influenced the behavioural outcome of communication. The model is best suited for communication campaigns that must reach large audiences to change their beliefs, attitudes and behaviour. McGuire characterises two sets of components as "input/output" matrix to be manipulated and measured when planning and evaluating communication campaigns. The list of input variables provides an option 
to the communication planner when designing the campaign.

The input components are the independent variables that are manipulated to achieve certain outputs. These are sources, messages, channels, receivers and intent. The source variable refers to the characteristics of the person who presents the message to the public. Sources can vary in number, demographics, and credibility. Messages may vary in type of appeal, information presented, organisation, and repetitions. The channel variable refers to the mass medium through which the message is transmitted to the public. It can also refer to delivery style and context. Receivers are the target audience. Like sources, receivers can vary in number, demographics, and lifestyles. The campaign intent reflects beliefs, attitudes and/or behaviour the planner desire to change and is the goal of the communication campaign (McGuire, 1989).

Within the context of the model twelve output variables are measured by examining the reactions of the public to the sources, messages, channels, receivers, and intent. These variables are similar to those in the diffusion model. The output variables are endpoint in communication campaigns and can be used to determine the campaigns level of success. These are exposure, attention, liking, comprehending the message in the communication campaign. They refer to getting the messages out to a wide audience, with clarity, appeal and understanding.

Acquiring skills, changing behaviour, remembering, and retrieving information are the bases for long-term changes in beliefs, attitudes, and behaviours. Deciding to act, change behav- iour, and reinforce a decision are the long-term changes communication campaigns often seek. Consolidating the results is essential to any communication campaign. Only through evaluating results can a campaign planner determine the success of communication campaigns (McGuire, 1989). Some of the input/output variables outlined by McGuire are considered in this paper. They include receiver (adolescents), messages, and behavioural outcomes.

This analysis presents an opportunity to use a unique data set to assess young people's exposure to messages in the media as opposed to channels of communication which have been the focus of most mass media research. The uniqueness of the data set lies in the fact that the data was collected from young people by young people thus making it possible for the respondents to express themselves openly. In addition, there was a deliberate effort to collect specific information on exposure to mass media channels and messages. The limitation of the data is the absence of information on description of the messages, content and the expected behavioural outcomes of the campaign messages. Also, the outcome variables used in this paper are mainly those that are related to HIV/AIDS risk perception and stigma and discrimination. This notwithstanding, it is possible to use the conceptual framework to assess aspects of the mass media campaign such as the message, channels and the receivers.

\section{Data and methods}

The paper used data from the National Survey of Adolescents conducted by 
the Guttmacher Institute in collaboration with the Institute of Social and $\square$ conomic Research, Legon, Ghana and the University of Cape Coast, Ghana, among adolescents aged between 12 19 years in Ghana. The total number of respondents for the survey was 4430 (2229 males and 220I females).

The 2003 Ghana Demographic and Health Survey (GDHS) served as a sampling frame. A first stage systematic selection of 200 enumeration areas ( $\square$ As) was made from the $412 \mathrm{GDHS}$ $\square$ As. A second stage selection of 48 households per $\square$ A was made from the update 2003 GDHS listing.

The variables used for this paper include socio-demographic characteristics of adolescents and exposure to messages on HIV/AIDS (which is a dichotomous variable) in the mass media. Simple cross tabulations and logistic regression analysis are employed to present the results. Cross tabulations are used in the first part of the analysis to describe the study population, frequency of exposure to mass media channels, exposure to mass media channels and messages.

The paper goes further to use two logistic regression models to establish the association between four outcome variables, namely - chances of getting HIV/AIDS; willingness to care for HIV/ AIDS infected persons; buying fresh vegetables from shop keepers with AIDS and keeping AIDS in the family a secret and exposure to messages in Model I. In Model 2, six covariates (age, sex, highest level of education, religion, ethnicity, place of residence) are added to exposure to messages to estimate their effects on the outcome variables. $\square$ xposure to messages had dichotomous response categories; these are exposure and no exposure. Respondents who responded 'Yes' to having seen/heard an HIV/AIDS message were coded $I$ and those who responded 'No' were coded 0 . In all, there were 9 messages.

\section{Results}

A total of 4548 adolescents made up of $50.4 \%$ males and $49.6 \%$ females were interviewed for this study (Table I). About $43 \%$ of males and $42 \%$ females were aged between 12-14 years at the time of the survey. The mean age of the respondents' was 15.2 years. More than $50 \%$ per cent of males and $46 \%$ of females had primary school education and there were more Akans among the respondents $(45.9 \%$ males and $48.8 \%$ females). Most of the respondents belonged to one religious group or the other. About $80 \%$ of the males and $73 \%$ of the females were Christians. About $54 \%$ males and $42 \%$ females lived in the countryside while $30 \%$ males and more than $23 \%$ females lived in cities. 
Table I Background characteristics of respondents

\begin{tabular}{|c|c|c|}
\hline \multirow[t]{2}{*}{ Characteristics } & \multicolumn{2}{|c|}{ Sex } \\
\hline & Males & Females \\
\hline Age groups & $N=2291$ & $N=2257$ \\
\hline $12-14$ & 43.1 & 42.0 \\
\hline $15-17$ & 37.8 & 38.7 \\
\hline $18+$ & 19.2 & 19.4 \\
\hline Level of $\square$ ducation & $N=2130$ & $N=2034$ \\
\hline Primary & 51.7 & 46.6 \\
\hline JSS/Middle & 39.2 & 42.8 \\
\hline SSS/Secondary & 9.4 & 9.8 \\
\hline Higher & 0.2 & 0.3 \\
\hline$\square$ thnicity & $N=2289$ & $N=2257$ \\
\hline Akan & 45.9 & 48.8 \\
\hline Ga-Adangbe & 6.1 & 7.2 \\
\hline$\square$ we & 13.4 & 14.2 \\
\hline Mole-Dagbani & 15.5 & 10.7 \\
\hline Guan & 19.1 & 19.1 \\
\hline Religion & $N=2291$ & $N=2257$ \\
\hline Traditional Religion & 7.6 & 4.7 \\
\hline Christian & 73.0 & 79.8 \\
\hline Muslim & 19.4 & 15.5 \\
\hline Place of residence & $N=2291$ & $N=2252$ \\
\hline Countryside & 54.0 & 41.6 \\
\hline Town & 16.0 & 35.2 \\
\hline City & 30.0 & 23.2 \\
\hline
\end{tabular}

Source: Computed from National Survey of Adolescents, 2004

Results in Table 2 indicate that the respondents were exposed to the mass media- radio, television and newspaper with variations in the frequency of exposure by sex. More males than females were exposed to the radio every day. For instance $42.8 \%$ males and $39.5 \%$ respectively were exposed to the radio almost every day. In the case of the television, about $33 \%$ males and $29 \%$ females were exposed to it at least once a week. A much lower exposure was recorded by the newspaper. 
African Population Studies Vol $\square 5$, I (April $\square 0 I$ I)

Table 2 Frequency of exposure to mass media channel by sex

\begin{tabular}{lcc}
\hline \multicolumn{1}{c}{ Channels } & Sex \\
\hline Radio & $\mathrm{N}=2287$ & Females \\
Almost everyday & 42.8 & $\mathrm{~N}=2253$ \\
At least once a week & 36.5 & 39.5 \\
Less than once a week & 12.8 & 34.4 \\
Not at all & 7.9 & 14.0 \\
Television & $\mathrm{N}=2289$ & 12.1 \\
Almost everyday & 20.2 & $\mathrm{~N}=2256$ \\
At least once a week & 32.6 & 28.0 \\
Less than once a week & 19.5 & 28.7 \\
Not at all & 27.7 & 15.4 \\
Print & $\mathrm{N}=2127$ & 27.9 \\
Almost everyday & 4.0 & $\mathrm{~N}=2029$ \\
At least once a week & 18.2 & 3.3 \\
Less than once a week & 13.3 & 20.9 \\
Not at all & 64.4 & 12.8 \\
\hline
\end{tabular}

Source: Computed from National Survey of Adolescents, 2004

Table $3 \square$ xposure to mass media messages by sex

\begin{tabular}{lcc}
\hline \multicolumn{1}{c}{ Sex } & \\
\hline \multicolumn{1}{c}{ Messages } & Males (N=229I) & $\begin{array}{c}\text { Females (N=2257) } \\
\text { Yes }\end{array}$ \\
\hline "Show compassion" & 40.3 & 40.5 \\
"Stop Aids-Love Life" & 75.0 & 70.0 \\
"It Pays to Wait" & 53.4 & 53.4 \\
"Say No to Casual Sex" & 53.4 & 52.1 \\
"No means no - think!" & 54.5 & 52.7 \\
"Things we do for love" & 56.0 & 56.0 \\
"If it's not on - it's not in" & 52.8 & 52.1 \\
"Don't go Mungo Park" & 13.2 & 12.7 \\
"Think Before you Play" & 42.9 & 33.8 \\
\hline
\end{tabular}

Source: Computed from National Survey of Adolescents, 2004

Data in Table 3 indicate that there are variations in the exposure of young people to messages on HIV/AIDS. For instance, $75 \%$ males and $70 \%$ females reported having been exposed to the message "Stop AIDS-Love Life".
Another $56 \%$ of males and females respectively had been exposed to the message "Things we do for Love". Only $13.2 \%$ males and $12.7 \%$ females indicated that they had been exposed to the message "Mungo Park". 
Table 4 Results on logistic regression analysis on chances of getting HIV/AIDS

\begin{tabular}{|c|c|c|}
\hline Variables & $\begin{array}{c}\text { Model I } \\
\text { Odds Ratio }\end{array}$ & $\begin{array}{c}\text { Model } 2 \\
\text { Odds Ratio }\end{array}$ \\
\hline \multicolumn{3}{|c|}{$\square \times x$ osure to Messages $(\mathrm{RC}=\mathrm{No})$} \\
\hline "Show compassion" & $1.194 * *$ & $1.296 * *$ \\
\hline "Stop AIDS-Love Life" & $1.224 *$ & $1.413 * *$ \\
\hline "It Pays to Wait" & 1.006 & 1.003 \\
\hline "Say No to Casual Sex" & $1.256 * *$ & 1.073 \\
\hline "No means no - think" & I.17I* & 1.148 \\
\hline "Things We Do for Love" & $0.704 * * * *$ & 0.952 \\
\hline "If it's not on - it's not in" & 1.152 & 0.906 \\
\hline “Don't go Mungo Park” & 0.999 & 0.905 \\
\hline "Think Before you play" & I.299** & I.270** \\
\hline \multicolumn{3}{|c|}{ Level of $\square$ ducation ( $R C=$ Primary) } \\
\hline Secondary & NA & 0.911 \\
\hline Tertiary & NA & 1.022 \\
\hline \multicolumn{3}{|c|}{ Age group $(R C=12-\mid 4)$} \\
\hline $15-17$ & NA & $1.695^{*} * *$ \\
\hline $18+$ & NA & $2.001 * * * *$ \\
\hline \multicolumn{3}{|c|}{ Place of origin $(\mathrm{RC}=$ Countryside $)$} \\
\hline Town & NA & 1.016 \\
\hline City & NA & $1.416^{* *}$ \\
\hline \multicolumn{3}{|c|}{$\operatorname{Sex}(R C=$ female $)$} \\
\hline Male & & 0.922 \\
\hline \multicolumn{3}{|c|}{ Wealth index $(\mathrm{RC}=$ Very poor $)$} \\
\hline Least poor & NA & 1.120 \\
\hline Less poor & NA & 1.161 \\
\hline Poor & NA & 0.837 \\
\hline More poor & NA & 1.131 \\
\hline \multicolumn{3}{|c|}{ Dthnicity (RC= Guan) } \\
\hline Akan & NA & 0.808 \\
\hline Ga-Adangbe & NA & I.696** \\
\hline Dwe & NA & I.564** \\
\hline Mole-Dagbani & NA & $4.065^{* * * *}$ \\
\hline \multicolumn{3}{|c|}{ Religion ( $\mathrm{RC}=$ No religion) } \\
\hline Christianity & NA & 0.985 \\
\hline Moslem & NA & 1.031 \\
\hline
\end{tabular}

$\mathrm{RC}=$ Reference Category $* * *<.001 * *<.05^{*}<.10$

Source: Computed from National Survey of Adolescents, 2004 
Table 4 presents estimates from two logistic regression models on adolescents' risk perception. Model I considered exposure to HIV campaign messages as the covariates while in Model 2, 6 other covariates were added to estimate their association with adolescents' HIV/AIDS risk perception. The results show that exposure to some of the messages was significantly related to adolescents' risk perception as shown in Models I and 2 in Table 4. For instance, adolescents who were exposed to HIV/AIDS message titled "Think before you play" were about I.3 times more likely to consider themselves of having a chance of getting HIV/ AIDS $(p<.05)$. Adolescents who were exposed to the message titled "Stop AIDS-Love Life" were more than 1.2 times more likely to consider themselves at risk of contracting HIV $(p<.10)$ as shown in Model I. Also, there was a significant association between adolescents who were exposed to the message "Say No to Casual Sex" and HIV risk perception $(p<.05)$. After controlling for level of education, age, sex, place of origin, wealth index, ethnicity and religion in Model 2, the association between exposure to the messages "Think before you play and "Stop AIDS-Love Life" and risk perception are almost similar in magnitude and direction. It must be mentioned though that the estimate in Model 2 for the former, was slightly lower than that in Model I. For the message "Say No to casual sex", the direction was similar to the estimates in Model I but the magnitude was different. The analysis further show in Model 2 that adolescents aged between 15-17 years were more than 1.6 times more likely to perceive themselves as having the chance of getting HIV/AIDS. This was even higher among those who were aged 18 years and above who reported a likelihood of more than a 2 times $(p<.00 \mathrm{I})$. With regards to place of origin, there was a significant relationship between those who originated from cities. They were more than 1.4 times more likely to have a higher risk perception. The results also show a significant relationship between ethnicity and adolescents risk perception. For instance, adolescents who belong to the Mole-Dagbanis' reported a higher risk perception. They were more than 4 times more likely to consider themselves as being at risk of HIV $(p<.00 \mathrm{I})$. Using some of the standard stigma and discrimination variables, the logistic regression analysis was used to assess how exposure to mass media messages affected adolescents' attitudes and behaviour towards people living with AIDS. Two Models were used to estimate association between exposure to messages (Model I) on one hand and messages and other covariates (Model 2) on the other and adolescents' willingness to care for an HIV infected person (see Table 5). The results from Model I indicated that adolescents' exposure to some of the messages had a significant association with willingness to care for HIV infected persons. It must be noted that this relationship was both direct and indirect. For instance, those who were exposed to the message "No means no-think" were more than I.2 times more likely to express willingness to care for HIV infected persons $(p<.05)$. This association, though direct in Model 2 for the same message, was not significant. 
Table 5 Results on logistic regression analysis on willingness to care for an HIV/ AIDS infected person

\begin{tabular}{|c|c|c|}
\hline Variables & $\begin{array}{c}\text { Model I } \\
\text { Odds Ratio }\end{array}$ & $\begin{array}{c}\text { Model } 2 \\
\text { Odds Ratio }\end{array}$ \\
\hline \multicolumn{3}{|c|}{$\square$ xposure to Messages $(\mathrm{RC}=\mathrm{No})$} \\
\hline "Show compassion" & $0.802 * *$ & 0.909 \\
\hline "Stop AIDS-Love Life" & $0.632 * * * *$ & $0.585 * * * *$ \\
\hline "It Pays to Wait" & 0.898 & 0.860 \\
\hline "Say No to Casual Sex" & $0.674 * * * *$ & $0.634 * * *$ \\
\hline "No means no - think" & $1.256 * *$ & 1.161 \\
\hline "Things We Do for Love" & $0.474 * * * *$ & $0.7 \mid 4 * * *$ \\
\hline "If it's not on - it's not in" & 0.886 & 0.895 \\
\hline "Don't go Mungo Park" & 1.033 & 0.933 \\
\hline "Think Before you play" & 1.121 & 1.130 \\
\hline \multicolumn{3}{|c|}{ Level of $\square$ ducation ( $R C=$ Primary) } \\
\hline Secondary & NA & $0.725 * *$ \\
\hline Tertiary & NA & $0.602 * *$ \\
\hline \multicolumn{3}{|c|}{ Age group $(R C=12-14)$} \\
\hline $15-17$ & NA & 0.900 \\
\hline $18+$ & NA & 0.983 \\
\hline \multicolumn{3}{|c|}{ Place of origin ( $\mathrm{RC}=$ Countryside) } \\
\hline Town & NA & $0.794 * *$ \\
\hline City & NA & $0.708 * *$ \\
\hline \multicolumn{3}{|c|}{ Sex $(R C=$ female $)$} \\
\hline Male & & 0.935 \\
\hline \multicolumn{3}{|c|}{ Wealth index (RC=Very poor) } \\
\hline Least poor & NA & 0.999 \\
\hline Less poor & NA & 1.066 \\
\hline Poor & NA & 0.841 \\
\hline More poor & NA & 0.942 \\
\hline \multicolumn{3}{|c|}{$\square$ thnicity (RC= Guan) } \\
\hline Akan & NA & 0.846 \\
\hline Ga-Adangbe & NA & $1.459 *$ \\
\hline Dwe & NA & 1.601 *** \\
\hline Mole-Dagbani & NA & 1.386 \\
\hline \multicolumn{3}{|l|}{ Religion $(\mathrm{RC}=$ No religion $)$} \\
\hline Christianity & NA & 1.106 \\
\hline Moslem & NA & 1.237 \\
\hline
\end{tabular}

$\mathrm{RC}=$ Reference Category**** $<.001 * *<.05 *<.10$

Source: Computed from National Survey of Adolescents, 2004 
On the other hand, exposure to the message "Stop AIDS-Love Life", though significant, had indirect associations with adolescent willingness to care for HIV infected persons. For example, estimates from both models showed that those who were exposed to this message were less likely to express willingness to care for HIV infected persons. The analysis further revealed that adolescents who belonged to the ethnic groups Ga-Adangbe and Dwe were more likely to express willingness to care for HIV infected persons. For instance, the $\square$ wes were 1.6 times more likely to express willingness to care for HIV infected persons. The covariates level of education, age, sex, wealth index and religion did not have any significant association with willingness to care for HIV infected persons.The results on whether adolescents were willing to buy fresh vegetables from shop keepers with AIDS revealed some interesting results. For instance, estimate from Model I shows that there was a statistically significant but indirect relationship between adolescents' exposure to some of the HIV/AIDS messages and adolescents' attitudes towards buying fresh vegetables from shop keepers with AIDS. However, in Model 2, adolescents who were exposed to the message "Think before you play" were more than I. 3 times more likely to buying fresh vegetables from shop keepers with AIDS. The effect of one's ethnicity suggested that adolescents who were Mole-Dagbanis' were about 2.3 times more likely to be willing to buy fresh vegetables from shop keepers with AIDS $(p<.05)$. Further analysis of Model 2 shows that most of the other covariates had an indirect association with adolescents' attitudes towards buying vegetables from shop keepers with AIDS. For instance, adolescents who had secondary education were about 0.78 percent less likely to express willingness to buy vegetables from shop keepers with AIDS $(\mathrm{p}<.05)$. It is interesting to note that, although the effects of covariates such as education and sex of adolescents' were significant, the associations were indirect. For instance, male adolescents were about 0.45 times less likely to express willingness to buy fresh vegetables from shop keepers with AIDS.

Table 6 Results on logistic regression analysis on buying fresh vegetable from shop keeper with AIDS

\begin{tabular}{lcc}
\hline \multicolumn{1}{c}{ Variables } & $\begin{array}{c}\text { Model I } \\
\text { Odds Ratio }\end{array}$ & $\begin{array}{c}\text { Model 2 } \\
\text { Odds Ratio }\end{array}$ \\
\hline $\begin{array}{c}\text { Dxposure to Messages (RC=No) } \\
\text { "Show compassion" }\end{array}$ & $0.839 *$ & \\
"Stop AIDS-Love Life" & $0.578^{* * *}$ & 0.843 \\
"It Pays to Wait" & $0.759 * *$ & $0.576 * *$ \\
"Say No to Casual Sex" & 0.879 & $0.755^{* * *}$ \\
"No means no - think" & 1.166 & 0.969 \\
"Things We Do for Love" & $0.637 * * *$ & 1.072 \\
"If it's not on - it's not in" & $0.749 * *$ & $0.743^{* * *}$ \\
"Don't go Mungo Park" & 1.197 & 0.835 \\
& & $1.297 *$
\end{tabular}




\begin{tabular}{|c|c|c|}
\hline "Think Before you play" & 1.156 & $1.354 * *$ \\
\hline \multicolumn{3}{|c|}{ Level of $\square$ ducation ( $R C=$ Primary) } \\
\hline Secondary & NA & $0.777 * *$ \\
\hline Tertiary & NA & $0.602 * *$ \\
\hline \multicolumn{3}{|c|}{ Age group $(R C=12-14)$} \\
\hline $15-17$ & NA & 0.895 \\
\hline $18+$ & NA & 0.959 \\
\hline \multicolumn{3}{|c|}{ Place of origin $(\mathrm{RC}=$ Countryside $)$} \\
\hline Town & NA & $0.737 * * *$ \\
\hline City & NA & $0.768 *$ \\
\hline \multicolumn{3}{|c|}{$\operatorname{Sex}(R C=$ female $)$} \\
\hline Male & NA & $0.448 * *$ \\
\hline \multicolumn{3}{|c|}{ Wealth index $(\mathrm{RC}=$ Very poor $)$} \\
\hline Least poor & NA & 0.943 \\
\hline Less poor & NA & 0.898 \\
\hline Poor & NA & $0.715 * *$ \\
\hline More poor & NA & $0.717 * *$ \\
\hline \multicolumn{3}{|c|}{$\square$ thnicity $(\mathrm{RC}=$ Guan $)$} \\
\hline Akan & NA & 1.040 \\
\hline Ga-Adangbe & NA & $\mathrm{I} .497$ \\
\hline Dwe & NA & $0.70 I^{*}$ \\
\hline Mole-Dagbani & NA & $2.349 * *$ \\
\hline \multicolumn{3}{|c|}{ Religion ( $\mathrm{RC}=$ No religion) } \\
\hline Christianity & NA & 1.048 \\
\hline Moslem & NA & 0.918 \\
\hline
\end{tabular}

$\mathrm{RC}=$ Reference Category*** $<.001 * *<.05 *<.10$

Source: Computed from National Survey of Adolescents, 2004

Table 7 presents the result on two times less likely to keep AIDS in the logistic regression models keeping AIDS family as a secret $(p<.05)$. However, in the family a secret. The results from the first model revealed that there were statistically significant but indirect relationships between exposure to most of the messages on HIV/AIDS except two of them. For instance, adolescents who were exposed to the message "Show compassion" were about 0.86 times less likely to keep AIDS in the family as a secret $(p<.05)$. Also, those who had seen the "Stop AIDS; Love Life" message were 0.62 with regards to the messages "No means no" and "Think before you play", adolescents who had seen these messages were more likely to keep AIDS in their family as a secret. For example, adolescents who had seen the message "Think before you play" were more than 1.2 times more likely to keep AIDS in the family as a secret. With regards to Model 2, it was only exposure to the message "Stop AIDS; 
tionship with keeping AIDS in the family as a secret. Adolescents who had tertiary education were more than 1.7 times more likely to keep AIDS in the family as a secret $(p<.001)$. The results further showed that adolescent males were 1.9 times more likely to keep
AIDS in the family as a secret $(p<.00 \mathrm{I})$. Although a direct effect was established between age and wealth index and keeping AIDS in the family a secret, the relationship was not significant (see Table 7).

Table 7 Results on logistic regression analysis on keeping AIDS in the family a secret

\begin{tabular}{|c|c|c|}
\hline Variables & $\begin{array}{l}\text { Model I } \\
\text { Odds Ratio }\end{array}$ & $\begin{array}{c}\text { Model } 2 \\
\text { Odds Ratio }\end{array}$ \\
\hline \multicolumn{3}{|c|}{ Dxposure to Messages $(\mathrm{RC}=\mathrm{No})$} \\
\hline "Show compassion" & $0.858 *$ & 0.866 \\
\hline "Stop AIDS-Love Life" & $0.622 * * * *$ & $0.64 I^{*} * * *$ \\
\hline "It Pays to Wait" & 0.866 & 0.857 \\
\hline "Say No to Casual Sex" & 1.139 & 1.079 \\
\hline "No means no - think" & I.187*** & 1.078 \\
\hline "Things We Do for Love" & $0.842 * *$ & 1.017 \\
\hline "If it's not on - it's not in" & 0.935 & 0.952 \\
\hline “Don't go Mungo Park” & 1.133 & 1.086 \\
\hline “Think Before you play” & $1.255^{* *}$ & 1.104 \\
\hline \multicolumn{3}{|c|}{ Level of $\square$ ducation ( $R C=$ Primary) } \\
\hline Secondary & NA & 1.113 \\
\hline Tertiary & NA & I.739**** \\
\hline \multicolumn{3}{|c|}{ Age group $(R C=12-14)$} \\
\hline $15-17$ & & 1.099 \\
\hline $18+$ & & 1.033 \\
\hline \multicolumn{3}{|c|}{ Place of origin ( $\mathrm{RC}=$ Countryside $)$} \\
\hline Town & NA & 0.861 \\
\hline City & NA & 0.832 \\
\hline \multicolumn{3}{|c|}{ Sex $(R C=$ female $)$} \\
\hline Male & NA & 1.931 **** \\
\hline \multicolumn{3}{|c|}{ Wealth index (RC=Very poor) } \\
\hline Least poor & NA & 1.112 \\
\hline Less poor & NA & 1.048 \\
\hline Poor & NA & 0.894 \\
\hline More poor & NA & 1.033 \\
\hline
\end{tabular}


-thnicity $(\mathrm{RC}=$ Guan)

Akan

NA

0.808

Ga-Adangbe

NA

$0.663 * *$

ঢwe

NA

$0.687 * *$

Mole-Dagbani

NA

1.386

Religion $(\mathrm{RC}=$ No religion $)$

Christianity

NA

0.925

Moslem

NA

1.015

$\mathrm{RC}=$ Reference Category $* * *<.00 I^{*} *<.05 *<.10$

Source: Computed from National Survey of Adolescents, 2004

\section{Discussion}

Using the input/output persuasion model by McGuire, the paper attempted to assess adolescents' exposure to mass media messages viz-a-viz HIV/AIDS behavioural outcomes. The results from the bivariate analysis on exposure showed that there were variations in the exposure of young people to messages on HIV/AIDS. The "Stop AIDS-Love Life" message was the most popular among the adolescents. For instance, $75 \%$ males and $70 \%$ females reported having been exposed to the message. Whilst only $13.2 \%$ and $12.7 \%$ indicated that they had been exposed to the message "Mungo Park". The low level of exposure to the message 'Mungo Park' could be due to the appeal of the message. The popularity of the "Stop AIDS-Love Life" can be attributed to the messages appeal and its repetitiveness. The title of the message was also the main theme of the campaign and, also, the phrase was highlighted in all the other messages thus the high exposure. Also, the message was a musical which had many popular musicians and characters young people could identify with. Thus, it is important to target adolescents with messages which are appealing to them.
According to the input/output persuasion model, independent variables are manipulated to achieve desire outcomes. The logistic regression was used to manipulate selected independent variables such as messages and receivers (adolescents - background characteristics) to establish the relationship between the inputs (messages and receivers) and outputs (behavioural outcomes). The logistic regression analysis revealed some interesting findings. Adolescents risk perception was affected by their exposure to some of the messages with exposure to messages like "Think before you play" and "Stop AIDS; Love Life having the highest magnitude and significance. In Model I, the message with the most significant effect on risk perception was the message "Think before you play". On the other hand, exposure to the message "Stop AIDS; Love Life" had the most significant effect on adolescents' risk perception in Model 2. It is however interesting to observe that adolescents age was significant in their risk perception with those aged 18 years and above having a higher risk perception. Also, adolescent who indicated that their place of origin was a city were more likely to have a higher risk per- 
ception. The association between exposure to messages and risk perception could be due to the popularity and clarity of these messages. This means that for adolescents' risk perception to be increased, the messages targeting that should be similar to those with the highest magnitude and significance. This could be one of the most effective ways of effecting behavioural change. Also, targeting a segment with a higher risk perception is likely to help in achieving the desired behaviour change.

Some interesting results emerge with regard to the logistic regression analysis on how exposure to mass media messages and other covariates affected adolescents' attitudes and behaviour towards AIDS stigma and discrimination. With regards to willingness to care for HIV/AIDS infected persons, the highest magnitude and significance were attained by the message "No means no - think". The estimate in Model 2 shows different effects with most of the associations being indirect after controlling for the 6 covariates. There were, however, some direct associations though these were not significant. Similar patterns were observed with regards to the other stigma and discrimination variables such as willingness to buy vegetables from shop keepers with AIDS and keeping AIDS in the family a secret. While some of the covariates had a direct and significant association with stigma and discrimination, others had an indirect and significant effect on it. It is noteworthy to state that adolescents who had tertiary education and were males were more likely to keep AIDS in the family as a secret. What this means is that for stigma reduction, it is important to put out messages which will enable adolescents to have a positive attitude towards people living with AIDS. Surprisingly, the other covariates - level of education, age, sex, wealth index and religion did not have any significant association with willingness to care for HIV infected persons. This situation could be an outcome of the taboo nature of issues surrounding sex and sexuality in the Ghanaian society given that heterosexual relationship is the main mode of transmission. These findings point to the extent to which stigma and discrimination are embedded in our society. If the country can derive the benefits from Anti-retroviral therapy, then it is important to put together an aggressive campaign to reduce or if possible eliminate HIV/AIDS stigma and discrimination; because it is only when stigma and discrimination is low that individuals will have a positive attitude towards HIV positive people.

\section{Conclusion}

Numerous studies have established the positive role of mass media channels in shaping people's behaviour towards different phenomenon including reproductive health over the years (Benefo, 2004; Hiddin et al., 1994; Khan et al., 2004; Kwankye et al., 2007). This paper focused on the role that the messages played in shaping adolescents' behaviour towards specific HIV/AIDS behavioural outcomes including risk perception and attitudes towards stigma and discrimination among other things.

The study revealed some interesting findings on the relationship between exposure to messages and 6 other covariates viz-a-viz HIV/AIDS behavioural 
outcomes. In a number of cases, exposure to messages contributed to some positive behavioural outcome while in others the magnitude and significance were higher after controlling for background variables. For a positive behavioural outcome to be achieved, it is imperative to put in place measures which will ensure that multiple messages are used. Also, it is imperative to segment adolescents' audience based on adolescents' needs, aspirations and concerns since the "one-size-fits-all" approach does not work in all cases.

For a positive behavioural outcome to be achieved, it is also important to put in place measures which will ensure that multiple messages are used. Also, it is imperative to segment adolescents' audience based on adolescents' needs, aspirations and concerns since the "one-size-fit-all" approach does not work in all cases.

Designers of HIV/AIDS campaign messages targeting adolescents should segment their target audience bearing in mind the heterogeneity which exists among a seemingly homogeneous population. Furthermore, attempts should be made to create conducive environments to enable young people to sustain positive behaviour they adopt in order not to "slip" or "relapse".

There is the need for further research to understand what explains the differences in attitudes towards HIV/AIDS stigma and discrimination especially by adolescents of different ethnic backgrounds.

\section{Acknowledgements}

The author would like to express his sincere gratitude to the Guttmacher Institute and all the collaborating institu- tions who worked on the Protecting the Next Generation. The project was funded by the Bill \& Melinda Gates Foundation, The Rockefeller Foundation and the Nationals Institute of Child Health and Human Development (Grant \# 5 R24 HD0436I0). I wish to also thank the anonymous reviewers and all my colleagues who read the initial drafts of this paper.

\section{References}

Annabel S.๑., Linus, I.A. \ttyang; Charles Onoka; Frederick Nyagah; Alex Muyonga. 2004. "Behavior Change Dvaluation of Culturally Consistent Reproductive Health Program for Young Kenyan". International Family Planning Perspectives, Vol. 30 No. 2 (June, 2004), pp 5867. Guttmacher, New York.

Benefo, K.D. 2004. "The Mass Media and HIV/AIDS Prevention in Ghana." Journal of Health and Population in Developing Countries. Department of Health Policy and Administration, School of Public Health, University of North Carolina at Chapel Hill.

Ghana Statistical Service (GSS), Noguchi Memorial Institute for Medical Research (NMIMR), and ORC Macro. 2004. Ghana Demographic and Health Survey [003. Calverton, Maryland: GSS, NMIMR, and ORC Macro.

Hindin, M. J., J. D. L. Kincaid, O. M. Kumah, W. Morgan, Y. M. Kim, J. K. Ofori. 1994. "Gender Differences in Media $\square x p o s u r e$ and Action during a Family Planning Campaign in Ghana." Health Communication 6 (2): 117 - 135.

Khan M.M.H, M Kabir, Mitsuru Mori. 2004. "Impact of various sources of 
AIDS information among ever married men and women in Bangladesh". Journal of Health and Population in Developing Countries. Department of Health Policy and Administration, School of Public Health, University of North Carolina at Chapel Hill.

Kim, Y., A. Kols, et al. 200 I. "Promoting sexual responsibility among young people in Zimbabwe." International Family Planning Perspectives 27(1): II-I9.

King, R. 1999. "Sexual Behavioural Change for HIV: Where Have the Theories Taken Us"? Geneva, UNAIDS.

Kwankye, S.O. and [. Augustt. 2007. "Media $\square$ xposure and Reproductive Health Behavior among Young Females in Ghana". African Population Studies, Vol. 22, No 2, pp 77-106.

Lewicky, N., K. Kiragu, et al. 1998. "Delivery of improved services for Health Project Uganda: Uvaluation of the safer sex or AIDS communication campaign". Johns Hopkins University Centre for Communication Programs Working Paper. May 1998.

National AIDS/STI Control Programme. 2009. "2008 HIV Sentinel Survey Reports". Ghana Health Services, Ministry of Health, Accra, Ghana.

National Population Council. 2000. "Adolescent Reproductive Health Policy". National Population Council, Accra, Ghana.

Piotrow, P., J. G. Rimon, K. Winnard, D. L. Kincaid, D. Huttington, J. Convisser. 1990. "Mass Media Family Planning Promotion in Three
Nigerian Cities". Studies in Family Planning 2I(5): 265 - 274.

Piotrow, P., D. L. Kincaid, M. J. Hindin, C. I. Lettenmaier, I. Kuseka. 1992. "Changing Men's Attitudes and Behavior: The Zimbabwe Male Motivation Project." Studies in Family Planning 23(6): 365 - 375.

Scheepers, 7. 200I. "The evaluation of Soul City 4: Interim Dxecutive Summary Report March 200I".

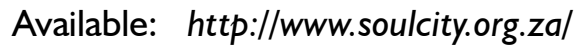
Series4Summary.htm Accessed Sep. 10, 2001

UNAIDS. 2007. "2008 Report on the global AIDS epidemic" Available: http://www.unaids.org/en/ KnowledgeCentre/HIVData/

GlobalReport/[ए008/

[008_Global_report.asp Assessed January, 2009.

Underwood, C. 200I. "Impact of the $H \square A R T$ campaign: Findings from the youth surveys in Zambia, 1999 \& 2000." Johns Hopkins Population Communication Services (PCS) Project Working Paper. July 200I.

Westoff, C. and G. Rodriguez. 1995. "The Mass Media and Family Planning in Kenya". International Family Planning Perspectives 2I(I): $26-31$.

Westoff, C. 1999. "Mass Communications and Fertility" in Dynamics of Values in Fertility Change. ed. R. Leyte. (Pp. 237 - 25I) Oxford, Oxford University press.

Yoder, S. P., R. Hornik, et al. 1996. "Шvaluating the Program effects of a Radio Drama about AIDS in Zambia." Studies in Family Planning 27(4): 188 - 203. 
African Population Studies Vol 25, I (April 20II) 